\title{
TRANSPORT/DIFFUSION COMPARISON FOR THE FFTF ENGINEERING MOCK-UP CRITICAL
}

G. E, Elanagan (ORNL) and D. L. Selby (UCCND-CSD)

In the current designs of fast reactors, the control monitoring during subcritical and low power operation will be based on data from ex-core detectors. These detectors are located in the radial shield of the Fast Flux Test Facility (FFTF) at approximately $113 \mathrm{~cm}$ from the core center. Eluxes in the area of the detectors are anisotropic and, therefore, the detector reaction rates could prove expensive to calculate.

A Iarge scale reactivity measurement experiment with the FFTF engineering mock-up critical core loaded into the 2PR-9 facility at Argonne National Laboratory was conducted in order to determine the adequacy of the low-level flux monitoring (LLFM) system in predicting the reactivity.

Numerous transport calculations have been performed at ORNL in support of the analysis of this experiment and have been reported previously. ${ }^{1}$

A mafor concern in interpreting the results of this experiment is the usefulness of diffusion theory in predicting the LLFM reactivities. Diffusion calculations were perfozmed for several of the experimental configurations.

The cross-section set used was identical to that used in the transport calculatfons reported in Reference (1) except that the usual transport corrected diffusion approximation was applied in which $\sigma_{t r}$ was obtained as shown below:

$$
\sigma_{t \mathbf{r}}(E)=\sigma_{T}(E)-\bar{\mu}_{\text {os }}(E) \sigma_{S}(E)
$$

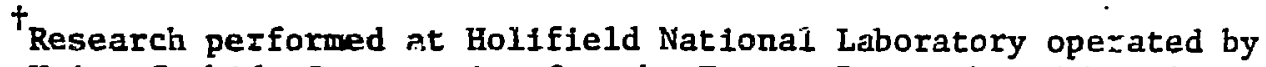
Union Carbide Corporation for the Energy Research and Development Administration. 
A comparison of the transport and diffusion results from both one-dimensional (cylindrical) and two-dimensional (X-Y) calculations are shown in Figs. 1 and 2, respectively.

Curve $A$ in both figures is a $S_{4} P_{3}$ transport calculation using zone-dependent and energy-dependent buckling to represent the leakage In the $\mathrm{Z}$ direction. The bucklings were obtained from three-dimensional KENO Monte Carlo calculations. ${ }^{2}$ The $\mathrm{S}_{4} \mathrm{P}_{3}$ distributions are in excellent agreement with experimentally measured detector and foil distributions and are considered "exact" for this comparison. Curve B in each figure indicates the same calculation using diffusion tineory. When compared to the $S_{4} P_{3}$ results (Curve $A$ ), the error is less than $3.5 \%$ over the core region in: one dimension and somewhat larger or the order of $10 \%-15 \%$ in parts of the core, for the two-dimensional calculation due to the explicit representation of control rods. However, the error reaches a maximum of $132 \%$ in one dimension and $184 \%$ in two dimensions near the widdle of the reflector region. The transport and diffusion results again tend towards agreement as one proceeds into the shield. Curve $C$ in Fig. 1 represents $a$ one-dimensional diffusion calculation in which the $\mathrm{Z}$ direction buckling is represented by a single value over all zones. The agreement with the $S_{4} P_{3}$ results is as reported in a previous transport approximation comparison. 3

These results indicate that the careful analysis of ex-core detection systems fis necessary. The methods used to represent the buckling are most important in judging the effectiveness of diffusion techniques. Similar comparisons vill be reported on the effect of diffusion and buckling on the blanket breeding ratio in an LMFBR critical mock-up. 


\section{REFERENCES}

1. G. F. Flanagan, D. B. Simpson, D. L. Selby, and J. T. Mihalczo, "Transport Calculation for Reactivity Measurement in Subcritical Configurations of the FFTF Engineering Mock-up Core," TRANSACTIONS OF THE AMIRICAN NUCLEAR SOCIETY ANNUAL MEETING held in Philadelphia, Pennsylvania, 18: 268, June, 1974.

2. L. H. Petrie and N. F. Cross, "Energy and Region-Dependent Bucklings for the FFTF Engineering Mock-up Core from Monte Car10," TRANSACTIONS OF THE AMERICAN NUCLEAR SOCIETY ANNUAL MEETING held at Philadelphia, Pernsylvania, 18: 348, June, 1974.

3. G. F. Flanagan, N. M. Greene, W. W. Engle, Jr., and E. T. Tomlinson, "Comparison of 'Transport Approximations for Reactor Physics Calculations in a Fast Reactor," TRANSACTIONS OF THE AMERICAN NUCLEAR SOCIEIY WINTER MEETING held in San Francisco, California, 17: 486, N̄oyember, 1973. 
$10 \mathrm{eL}^{-5}$

9

8

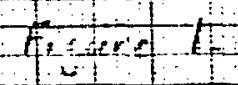

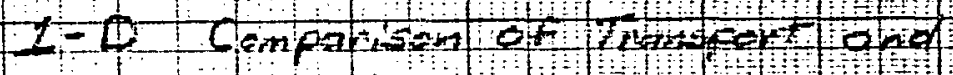

Diffusing Theny Dotadth

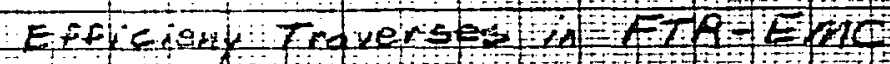

6

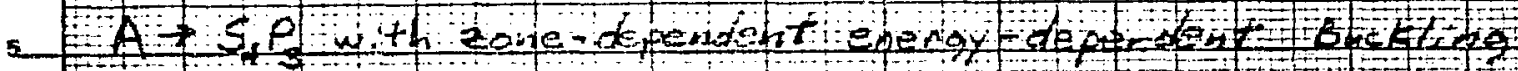

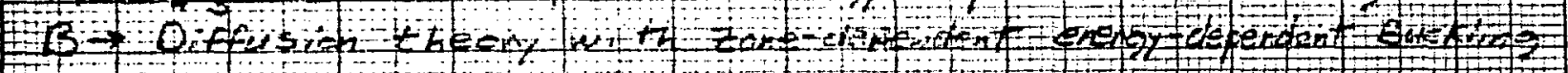

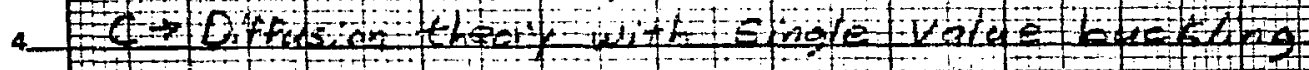

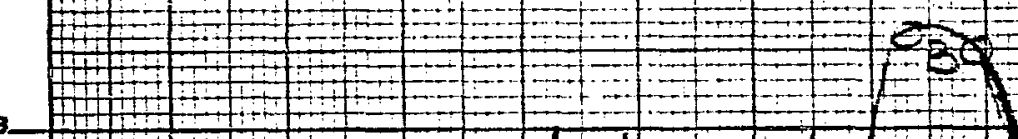

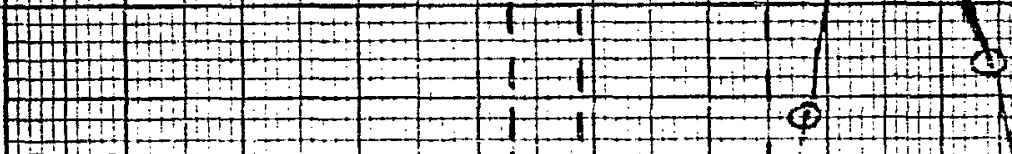
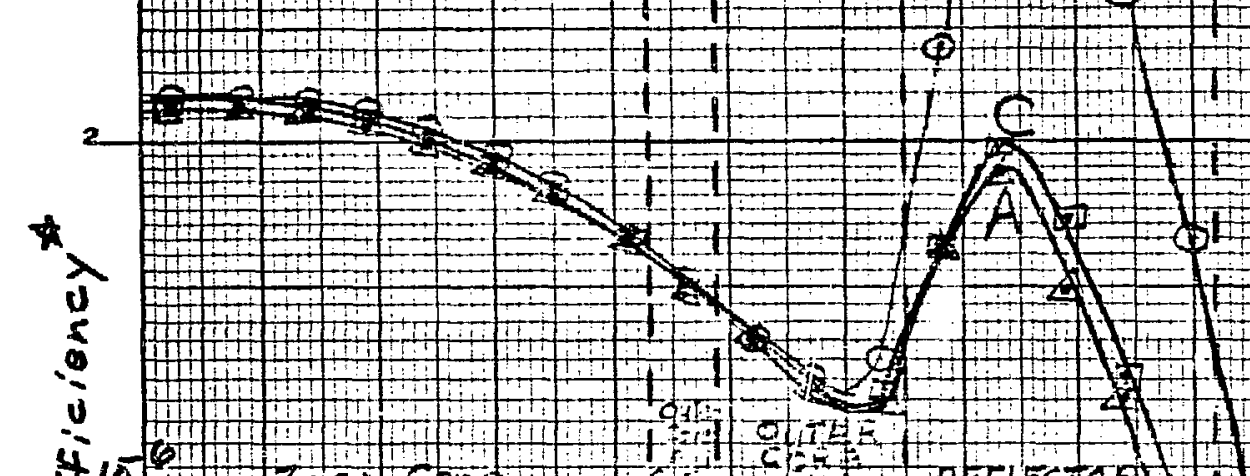

C

4.10

$7 \operatorname{tgn} x^{2} \cos s$

का ol

REFLECTOAI I \&AHELO

$4 \mathrm{~g}$

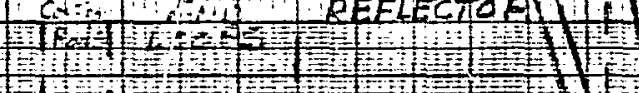

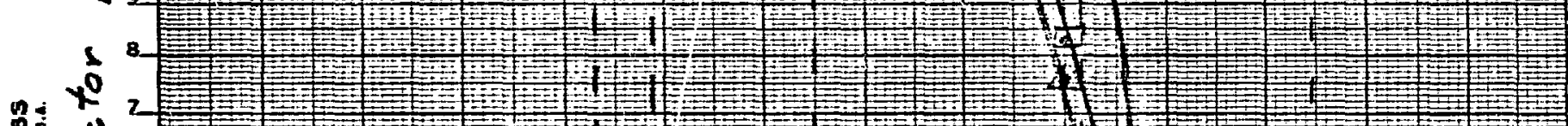

兽影

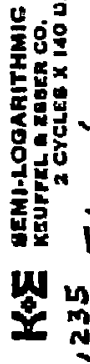

$6+1 \geq \square$

(1)

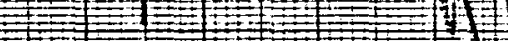

5

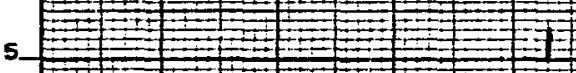

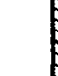

4

$+$

$+$

$+1$

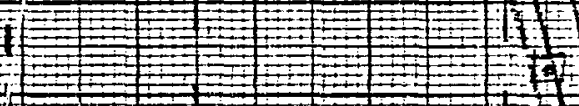

in

3

$1+1+111$
$1+1+1+1+1$

m

J

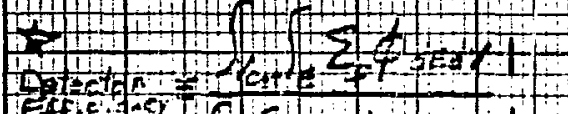

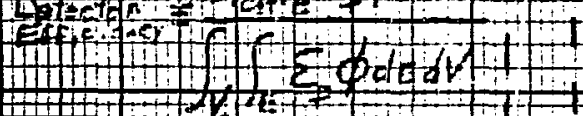

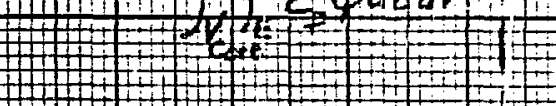

$10^{-7}$

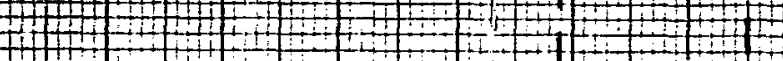

Ifif!

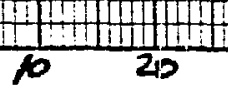

$\frac{1+1}{40}$

6

70 \&5

$\%$

100

110

(20 
$1210^{-5}$

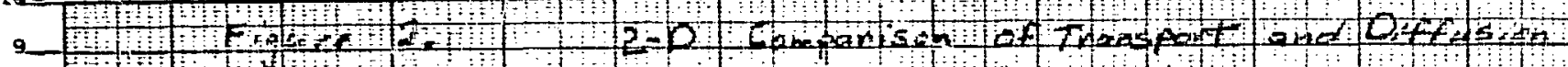

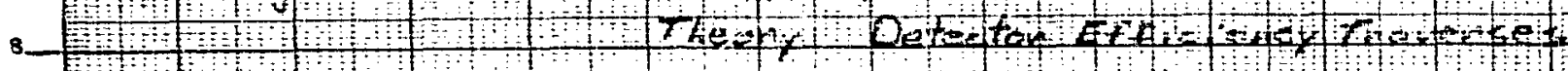

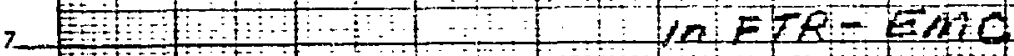

6

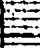

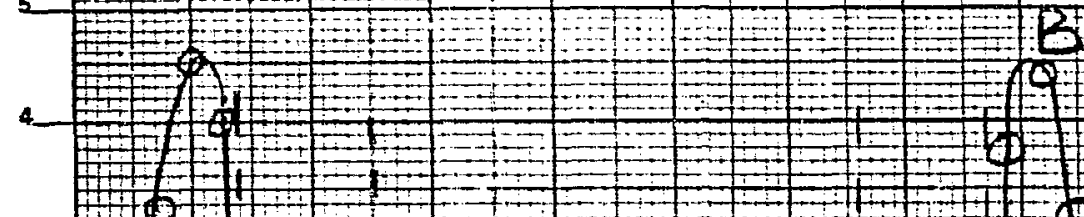

$+1-1+1+1+1+1+0$

3

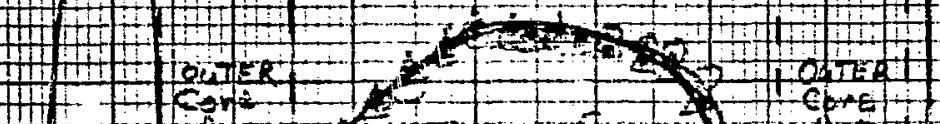

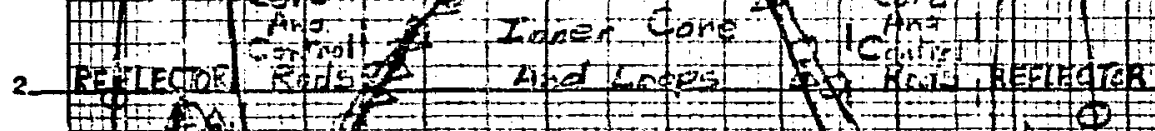

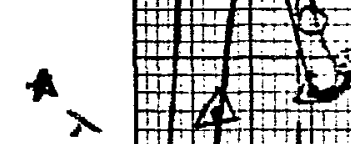

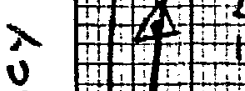

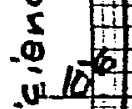

42 .

$4_{8}$

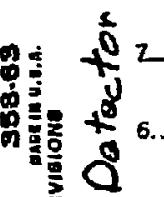

品

6

to

$+1+1$
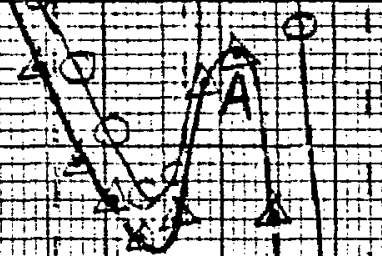

$i_{4}$

$u^{4}$

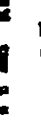

$\sum_{\substack{n \\ N}}^{n} 3$

I1+ 1

$+1+1+10$

2-

1

$1 \geq 1 \geq 1 \geq 1$

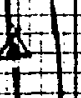

